\title{
Manajemen Pemanenan Kelapa Sawit (Elaeis guineensis Jacq.) di Kebun Gunung Pamela, Sumatera Utara
}

\author{
Harvesting Management of Oil Palm (Elaeis guineensis Jacq.) in Gunung Pamela Plantation, \\ North Sumatera
}

\author{
Husein Habib, dan Adolf Pieter Lontoh ${ }^{1 *}$ \\ ${ }^{1}$ Departemen Agronomi dan Hortikultura, Fakultas Pertanian, Institut Pertanian Bogor \\ (Bogor Agricultural University), J1. Meranti, Kampus IPB Darmaga, Bogor 16680, Indonesia \\ Telp.\&Faks.62-251-8629353 e-mail agronipb@indo.net.id \\ *Penulis korespondensi: alfpiton@yahoo.com
}

Disetujui 4 Mei 2016/ Published online 9 Mei 2016

\begin{abstract}
Reseach program gave knowledge, skill, and experience in technical aspect of conducting of oil palm and lead of the employees management. This activity was started from February to June 2013 in Gunung Pamela Plantation North Sumatera. Observation was examined with statistical data analyse such as corelation and t-dunnet test. Harvest rotation, harvest density, management of labour, and harvesting supervision were important aspect in harvesting activity. Result of harvest density estimation analysis was not significantly different, the result of corelation to harvester quality was observe from the age harvester, work experience and education level to output of harvester (amount of palm oil fruit) was not significantly different, weak, and directional except education level that a instruct contrary. Result of $t$-dunnet test of work experience didn't affect the real output of harvester. The age of harvester that less than and more than 30 years old, according to result of t-dunnet test, was not significantly different to the output. Productivity of palm oil in Gunung Pamela Plantation haven't reached to marihat standard.
\end{abstract}

Key words: Gunung Pamela Plantation, harvesting management, oil palm

\begin{abstract}
ABSTRAK
Kegiatan penelitian memberikan ilmu, keterampilan dan pengalaman tambahan dalam aspek teknis budidaya kelapa sawit maupun manajerial dalam mengkoordinasikan karyawan. Kegiatan berlangsung dari bulan Februari hingga Juni 2013 di kebun Gunung Pamela Sumatera Utara. Pengamatan diuji menggunakan analasis data statistika yaitu korelasi dan uji $t$-student. Rotasi panen, angka kerapatan panen, manejemen tenaga kerja, dan pengawasan panen merupakan aspek penting dalam kegiatan panen. Dari hasil analisis yang dilakukan, nilai akp estimasi dengan realisasi tidak berbeda nyata, hasil korelasi terhadap kualitas pemanen yang dinilai berdasarkan umur pemanen, lama kerja, dan tingkat pendidikan terhadap output pemanen (jumlah tandan) menunjukkan sifat yang tidak nyata, lemah, dan searah kecuali tingkat pendidikan yang bersifat berlawanan arah. Hasil uji t-student terhadap lama kerja menunjukkan bahwa lama kerja pemanen tidak berpengaruh nyata terhadap output yang dihasilkan. Umur pemanen yang kurang dari 30 tahun dan lebih dari 30 tahun menurut hasil uji-t ternyata berpengaruh tidak nyata pula terhadap output yang dihasilkan pemanen. Produktivitas kelapa sawit di kebun Gunung Pamela belum sesuai dengan standar marihat.
\end{abstract}

Kata kunci: Kebun Gunung Pamela, manajemen pemanenan, kelapa sawit 


\section{PENDAHULUAN}

Kelapa sawit (Elaeis guineensis Jacq.) adalah tanaman yang paling produktif dengan produksi minyak per hektar yang paling tinggi dari seluruh tanaman penghasil minyak nabati lainnya (Pahan, 2008). Tanaman kelapa sawit merupakan tanaman penghasil minyak yang telah lama dibudidayakan dan merupakan salah satu komoditas ekspor non migas yang berperan penting dalam perekonomian Indonesia sehingga menjadikan tanaman kelapa sawit sebagai primadona penghasil devisa negara dari sektor perkebunan.

Berdasarkan data dari Ditjenbun (2011) produksi minyak kelapa sawit meningkat seiring dengan pertambahan luas areal perkebunan kelapa sawit dan produksi tandan buah segar. Data menunjukan pada tahun 2008 terdapat 7363847 ha luas areal kelapa sawit dengan produksi CPO sebesar 18141006 ton dan di tahun 2010 meningkat menjadi 8430027 ha dengan produksi CPO 20615958 ton.Volume ekspor minyak kelapa sawit juga menunjukkan data yang terus meningkat setiap tahunnya. Ekspor minyak kelapa sawit pada tahun 2008 mencapai 18141006 ton dan pada tahun 2010 mengalami peningkatan dengan volume ekspor 20615959 ton. Minyak sawit merupakan produk perkebunan yang memiliki prospek yang cerah karena seiring berjalannya waktu, industri-industri yang berbasis bahan baku produk kelapa sawit meningkat pesat.

Teknik budidaya yang diterapkan di kebun terdiri atas kegiatan pembukaan lahan hingga penanganan pasca panen. Salah satu teknik budidaya utama dalam pengusahaan kelapa sawit adalah pemanenan. Panen adalah pemotongan tandan buah segar dari pohon hingga pengangkutan ke pabrik kelapa sawit (PKS). Keberhasilan pemanenan akan menunjang pencapaian produktivitas tanaman. Sebaliknya, kegagalan akan menurunkan produktivitas tanaman kelapa sawit. Pemeliharaan yang sudah baku dan potensi tinggi tidak berarti jika pemanenan tidak optimal (PPKS, 2007).

Kegiatan pemanenan memiliki tujuan untuk mendapatkan hasil panen dengan mutu yang baik. Tindakan yang dilakukan untuk mencapai tujuan pemanenan antara lain (a) pelaksanaan ketentuan panen seperti sistem panen, rotasi panen, kriteria matang panen dan persentase brondolan, (b) pelaksanaan angkutan panen segera mungkin ke pabrik dan (c) pelaksanaan pengolahan secepat mungkin (Astra Agro Niaga 1996). Kegiatan penelitian yang dilaksanakan mempunyai dua tujuan, yaitu tujuan umum dan khusus. Tujuan umum kegiatan penelitian adalah untuk menambah pengetahuan tentang perkebunan kelapa sawit, melatih keterampilan dan kemampuan dalam bidang perkebunan, memperoleh pengalaman kerja secara langsung, serta dapat mempelajari teknik budidaya serta manajemen perkebunan kelapa sawit. Tujuan khusus yang ingin dicapai adalah mempelajari manajemen pemanenan secara teknis, pengelolaan, dan menganalisis produksi yang dihasilkan

\section{BAHAN DAN METODE}

Pelaksanaan penelitian dilaksanakan di Kebun Gunung Pamela, Sumatera Utara. Pelaksanaan penelitian dilaksanakan selama empat bulan yakni pada bulan Februari sampai Juni 2013. Kegiatan penelitian yang dilakukan penulis di kebun Gunung Pamela adalah seluruh pekerjaan yang mengarah pada pengelolaan produksi di berbagai tingkat jabatan secara teknis dan manajerial dimulai dari KHL hingga asisten afdeling. Aspek teknis dilakukan pada tingkat jabatan sebagai karyawan harian lepas (KHL) selama satu bulan. Jenis kegiatannya adalah pemeliharaan dan pemanenan kelapa sawit. Kegiatan pemeliharaan yang dilakukan diataranya pemeliharaan jalan, penunasan (pruning), pemupukan, pengendalian gulma, hama dan penyakit. Aspek manajerial penulis lakukan pada tiga bulan berikutnya dengan rincian sebagai pendamping mandor yaitu mandor panen, mandor penyemprotan, mandor babat gulma manual, dan mandor pemupukan selama satu bulan dan sebagai pendamping asisten afdeling selama dua bulan terakhir.

Pengumpulan data dan informasi menggunakan metode langsung untuk data primer dan metode tidak langsung untuk data sekunder. Data primer diperoleh melalui pengamatan langsung ke lapangan seperti aktif dalam kegiatan di kebun, wawancara dan diskusi langsung dengan karyawan kebun, mandor dan asisten kebun. Pengamatan utama pengumpulan data primer dan informasi adalah kegiatan panen seperti kriteria matang panen, rotasi panen, taksasi produksi dan tenaga kerja. Pengamatan pada tahap panen dilakukan pada teknik pemotongan tandan, pengumpulan brondolan. Pada kegiatan pengumpulan tandan ke TPH diamati ada atau tidaknya tandan afkir dan tandan mentah, pemotongan tangkai tandan, dan pelepah tidak dipotong dua dan tidak disusun.

Pengumpulan data sekunder dan informasi dilakukan dengan mengumpulkan data dari laporan manajemen (bulanan, triwulanan, semesteran, tahunan) yang merupakan arsip di 
kantor kebun dan studi pustaka seperti kondisi umum lokasi seperti letak geografis dan keadaan lingkungan perkebunan. Data sekunder lain adalah data produksi perusahaan selama 5 tahun terakhir.

Analisis yang digunakan untuk mengolah data adalah analisis secara deskriptif dan kuantitatif. Analisis deskriptif digunakan untuk mencari nilai rata-rata dan persentase yang kemudian akan dideskripsikan dengan pembanding norma baku dan standar yang berlaku diperusahaan ataupun melalui studi pustaka dan literatur. Analisis kuantitatif digunakan dengan menggunakan analisis statistik uji korelasi dan uji t-student. Uji korelasi digunakan untuk mengetahui hubungan korelasi berbagai faktor pada aspek pemanenan dengan hasil panen yang diperoleh. Uji t-student digunakan untuk membandingkan suatu data yang diperoleh penulis dengan data yang sudah ada pada tahuntahun sebelumnya. Pengamatan yang dilakukan adalah :

Rotasi panen. Pengamatan rotasi panen dilakukan dengan membandingkan rotasi panen pada semester I dan semester II.

Kerapatan panen. Pengamatan angka kerapatan panen (AKP) dilakukan pada tanaman kelapa sawit dengan tahun tanam yang berbeda.

Tenaga kerja panen. Pengamatan dilakukan terhadap output pemanen berdasarkan lama kerja pemanen (pengalaman), umur pemanen dan tingkat pendidikan pemanen. Pengamatan dilakukan pada 12 orang pemanen dengan ulangan sebanyak empat kali ulangan.

Kualitas panen. Pengamatan pada mutu buah dilakukan di TPH dengan mengamati jumlah buah mentah, buah matang dan buah sakit. Pengamatan pada tingkat kesalahan pemanen seperti brondolan tidak dikutip, tidak menurunkan pelepah, curi buah dan tangkai tandan panjag.

Produktivitas per kapveld. Membandingkan produktivitas antar kapveld di empat kapveld yang berbeda dan masing masing kapveld diambil satu blok contoh.

Uji statistik. Uji statistik yang digunakan untuk menganalisis data yang diperoleh adalah uji korelasi dan uji t-student.

\section{HASIL DAN PEMBAHASAN}

\section{Manajemen Pemanenan Kelapa Sawit}

Manajemen $\begin{array}{cr}\text { adalah } & \text { proses } \\ \text { kerja }\end{array}$
mengkoordinasikan aktivitas-aktivitas
sehingga dapat selesai secara efektif dan efisien
dengan dan melalui orang lain. Proses manajemen
terdiri dari merencanakan (planning),

mengorganisasikan (organizing), memimpin (leading), dan mengawasi (controlling) (Robbins dan Coulter, 2005). Pada proses kegiatan pemanenan kelapa sawit, perencanaan mencakup kegiatan AKP (angka kerapatan panen) yang terdiri atas estimasi produksi, jumlah pemanen dan jumlah armada yang dibutuhkan, dan rotasi panen. Pengorganisasian mencakup struktur organisasi afdeling, pembagian pemanen menjadi dua kemandoran dan pembagian hanca panen. Kepemimpinan mencakup pada pelaksanaan panen yakni memastikan adanya alat pelindung diri (APD), kelengkapan alat alat panen dan bertanggung jawab atas seluruh kegiatan teknis di afdeling. Pengawasan mencakup kualitas buah yang dipanen, tangkai tandan dipotong pendek dan dibuat huruf $\mathrm{V}$, brodolan dikutip, pelepah dipotong dan disusun, dan tidak ada buah yang tertinggal di hanca maupun TPH.

\section{Rotasi Panen}

Rotasi panen adalah selang waktu antara panen yang satu dengan panen berikutnya pada satu hanca panen. Rotasi panen yang ideal adalah 7 hari (PPKS, 2003). Kegiatan pemanenan memerlukan rotasi panen untuk mengetahui berapa hari dalam satu minggu kegiatan panen harus dilakukan. Terdapat dua rotasi panen dalam kegiatan pemanenan di Kebun Gunung Pamela yaitu 5/7 dan 6/7. Rotasi panen 5/7 artinya adalah kegiatan pemanenan dilakukan dalam jangka waktu 5 hari dalam seminggu sedangkan rotasi panen 6/7 artinya kegiatan pemanenan dilakukan 6 hari dalam seminggu. Rotasi panen 5/7 dilakukan pada semester I sedangkan rotasi panen 6/7 dilakukan pada semester II (Tabel 1). Hal ini disebabkan produksi pada semester I lebih rendah dibandingkan semester II sehingga kekurangan produksi dapat ditutupi oleh produksi pada semester II.

Rotasi panen bermanfaat menjaga mutu buah dan kualitas buah yang akan dipanen. Rotasi panen yang terlalu cepat akan mengakibatkan banyaknya buah yang tidak bisa dipanen atau penurunan potensi buah (buah trek). Rotasi panen yang terlalu lambat dapat mengakibatkan tingginya losses seperti buah lewat matang (fraksi 4 dan 5), buah busuk, dan banyaknya brondolan tidak terkutip. Sarimanah (2008) menyatakan rotasi panen yang panjang akan mengakibatkan banyaknya jumlah brondolan yang disebabkan banyaknya tandan matang dan lewat matang di pohon. Hal tersebut mengakibatkan peluang kehilangan hasil berupa tandan matang tertinggal di pohon dan brondolan tidak dikutip menjadi 
sangat tinggi, sehingga menurunkan produksi dan produktivitas. Rotasi panen yang terlalu cepat (dibawah 7 hari) dapat mengakibatkan pemanen cenderung memanen buah mentah (under ripe) untuk memenuhi basis panen.

Tabel 1. Rotasi panen Kebun Gunung Pamela

\begin{tabular}{clcl}
\hline \multicolumn{3}{c}{ Semester I } \\
Kapveld & Hari & $\begin{array}{c}\text { Rata rata luas } \\
\text { kapveld panen }\end{array}$ & Luas \\
& & ---------Ha--------- \\
I & Senin & 94.816 & 96.09 \\
II & Selasa & 94.816 & 74.09 \\
III & Rabu & 94.816 & 87.71 \\
IV & Kamis & 94.816 & 97.31 \\
V & Jum'at & 69.186 & 93.24 \\
\hline & \multicolumn{3}{c}{ Semester II } \\
Kapveld & Hari & Rata rata luas \\
& \multicolumn{3}{c}{ kapveld panen } \\
I & Senin & 78.3 & 70.04 \\
II & Selasa & 78.3 & 69.18 \\
III & Rabu & 78.3 & 69.18 \\
IV & Kamis & 78.3 & 79.16 \\
V & Jum'at & 56.94 & 80.72 \\
VI & Sabtu & 78.3 & 58.59 \\
\hline
\end{tabular}

Sumber : Kantor Afdeling V, Kebun Gunung Pamela 2103

\section{Angka Kerapatan Panen}

Angka kerapatan panen (AKP) merupakan metode taksasi produksi untuk memperkirakan jumlah produksi, kebutuhan tenaga panen, dan kebutuhan armada esok hari. AKP dihitung sehari sebelum kegiatan panen dilakukan. Pelaksanaan kegiatan AKP dilakukan oleh krani AKP. Kegiatan AKP dilakukan siang atau sore hari. Tahapan dalam kegiatan AKP dimulai dengan menetapkan blok sampel untuk setiap kapveld yang akan dipanen esok hari. Pengambilan sampel dilakukan pada satu blok sampel mewakili tiap tahun tanam. Jumlah sampel minimal 3-5\% dari jumlah pohon dalam satu blok sampel. Tahap selanjutnya, ditetapkan baris sampel dalam setiap blok sampel dan seluruh pohon dalam baris sampel dihitung dan dicatat jumlah tandan matang (Tabel 2).

Nilai AKP yang terlalu tinggi dapat diartikan rendahnya jumlah tandan yang akan dipanen untuk esok hari. Nilai AKP yang rendah menyebabkan tingginya jumlah tandan yang dapat dipanen oleh pemanen sehingga menyebabkan losses. Berikut disajikan perhitungan AKP :

$$
\begin{aligned}
\text { AKP }: & \frac{\text { Jumlah pohon sampel }}{\text { Jumlah tandan buah matang }}: 1 \\
& : \frac{100}{10}: 1 \\
& : 10: 1
\end{aligned}
$$

Artinya dalam 10 pohon di lapangan terdapat 1 tandan buah matang. Selanjutnya perbandingan AKP digunakan untuk menentukan jumlah produksi dan unit transportasi esok hari dengan perhitungan sebagai berikut:

$$
\begin{aligned}
& \text { Produksi } \quad=\frac{\text { Jumlah pokok produktif }}{A K P} \\
& \quad=\frac{9360 \text { pokok }}{10}=936 \text { tandan } \\
& \text { Jumlah produksi }=\text { Produksi } \times \text { BJR } \\
& =\left(936 \text { tandan x } 17 \mathrm{~kg} \mathrm{tandan}^{-1}\right) \\
& =15912 \mathrm{~kg} \text { hari }^{-1} \sim 15.9 \text { ton hari }^{-1} \\
& \text { Jumlah kendaraan }=\frac{\text { Jumlah produksi }^{8}}{8500 \mathrm{~kg}} \\
& =\frac{15912 \mathrm{~kg}}{8500 \mathrm{~kg}}=1.87 \text { truk }=2 \text { truk }^{2}
\end{aligned}
$$

Berdasarkan hasil pengamatan pada Tabel 11, penentuan AKP di kebun belum terealisasikan dengan baik. Hal ini terlihat pada selisih antara estimasi dan realisasi produksi diatas $5 \%$. Setiawan (2012) menyatakan perbandingan hasil estimasi dengan realisasi lebih dari 5\% dapat disebabkan oleh perubahan pemetakan blok baru dengan menggabungkan tiga atau lebih blok lama menjadi satu hamparan blok lama menjadi satu hamparan blok baru yang mengakibatkan adanya perbedaan tahun tanam dalam satu blok. Penggabungan blok tersebut menjadikan unit kebun melakukan pemutihan terhadap tahun tanam.

Pengambilan tahun tanam pada satu hamparan berdasarkan persentase paling besar tahun tanam pada hamparan kelapa sawit. Pada teknis dilapangan, perbedaan dapat disebabkan sedikitnya sampel contoh yang diambil. Faktor lain yang dapat menyebabkan perbedaan estimasi dengan realisasi diatas 5\% adalah kegiatan AKP belum sesuai dengan instruksi kerja. Petugas AKP hanya memperkirakan berdasarkan hasil panen sebelumnya tanpa melakukan perhitungan jumlah tandan matang pada pokok sampel. Hasil uji-t AKP estimasi dengan realisasi antar tahun tanam menunjukan hasil yang tidak berbeda nyata. Artinya selisih umur tanaman 2 tahun tidak mempengaruhi potensi dan realisasi produksi kelapa sawit. Hal ini disebabkan penggunaan bibit kelapa sawit dari varietas dan asal bibit yang sama yaitu varietas tenera dari PPKS dan Socfindo. 
Tabel 2. Angka kerapatan panen per tahun tanam

\begin{tabular}{|c|c|c|c|c|c|c|c|c|}
\hline \multirow[b]{2}{*}{$\begin{array}{l}\text { Tahun } \\
\text { tanam }\end{array}$} & \multirow[b]{2}{*}{ Blok } & \multicolumn{2}{|c|}{ Jumlah pokok } & \multirow[b]{2}{*}{$\begin{array}{c}\text { Buah } \\
\text { matang }\end{array}$} & \multirow[b]{2}{*}{ AKP } & \multicolumn{2}{|c|}{ Jumlah produksi } & \multirow{2}{*}{$\begin{array}{l}\text { Selisih } \\
\text { jumlah } \\
\text { produksi } \\
(\%)\end{array}$} \\
\hline & & Seluruh & Dihitung & & & Estimasi & Realisasi & \\
\hline 2000 & $\mathrm{U} 25$ & 6490 & 106 & 13 & $8.15: 1$ & 4522 & 4092 & 10.51 \\
\hline 2000 & $\mathrm{O} 22$ & 5227 & 104 & 12 & $8.66: 1$ & 2295 & 2227 & 3.05 \\
\hline 2000 & Q18 & 6079 & 103 & 9 & $11.44: 1$ & 3417 & 2308 & 48.05 \\
\hline 1998 & $\mathrm{~N} 23$ & 830 & 95 & 10 & $9.5: 1$ & 476 & 194 & 145.36 \\
\hline 1998 & $\mathrm{O} 21$ & 653 & 95 & 26 & $3.65: 1$ & 833 & 586 & 42.15 \\
\hline 1998 & M23 & 830 & 95 & 10 & $9.5: 1$ & 272 & 329 & -17.33 \\
\hline Rata Rat & & 3351.50 & 99.67 & 13.33 & $8.15: 1$ & $1969.17^{\text {tn }}$ & $1622.67^{\mathrm{tn}}$ & 21.354 \\
\hline
\end{tabular}

Sumber : Pengamatan penulis April (2013)

\section{Tenaga Kerja Panen}

Kegiatan panen membutuhkan manejemen tenaga kerja yang baik sehingga dapat menghasilkan produksi sesuai dengan target yang ingin dicapai. Pembagian tenaga kerja harus dilakukan secara merata pada setiap hanca yang ingin dipanen sesuai dengan kriteria dan kemampuan para pemanen. Tenaga kerja panen merupakan karyawan yang bertugas untuk memotong pelepah, menurunkan tandan buah segar (TBS) dari tanaman kelapa sawit, memotong tangkai tandan, memberi nomor pada setiap TBS dan mengumpulkannya ke setiap tempat pengumpulan hasil (TPH). Kekurangan tenaga kerja pemanen akan mengakibatkan tidak tercapainya target produksi. Kekurangan tenaga kerja dapat disebabkan oleh banyaknya cuti karyawan, sakit, faktor alam seperti hujan saat jam kerja dan pemanen yang tidak sesuai dengan kompetensi. Persentase kehadiran pemanen disajikan pada Tabel 3 .
Tabel 3. Persentase kehadiran pemanen

\begin{tabular}{cccc}
\hline Mandor & $\begin{array}{c}\text { Jumlah } \\
\text { pemanen }\end{array}$ & $\begin{array}{c}\text { Rata-rata } \\
\text { kehadiran }\end{array}$ & $\%$ \\
\hline 1 & 11 & 9 & 81,82 \\
2 & 11 & 10 & 90,91 \\
\hline
\end{tabular}

Sumber : Hasil pengamatan penulis April 2013

Pada Tabel 12 rata-rata ketidakhadiran kedua kemandoran terdapat paling tinggi terdapat pada mandoran 1, sedangkan paling rendah terdapat pada mandoran 2. Ketidakhadiran para pemanen disebabkan oleh sakit dan cuti. Tingginya persentase ketidakhadiran dapat mengakibatkan target produksi harian tidak tercapai dan hanca yang akan dipanen menjadi tidak terpanen. Ketidakhadiran akibat karyawan tidak hadir tanpa izin akan diberikan sanksi secara tegas berupa surat peringatan. Apabila sudah diberikan tiga kali surat peringatan maka sesuai dengan peraturan perusahaan karyawan akan dimutasikan ke kebun yang lain. Hal ini bermaksud untuk meningkatkan kedisiplinan karyawan.

Tabel 4. Uji korelasi terhadap kualitas pemanen

\begin{tabular}{ccccc}
\hline \multirow{2}{*}{ Variabel } & Statistik uji & & Variabel & \\
\cline { 3 - 4 } & r (Koefisien) & Umur pemanen & Lama kerja & Tingkat pendidikan \\
\hline Lama kerja & P Value & $0.885^{* *}$ & \\
Tingkat pendidikan & r (Koefisien) & -0.000 & \\
& P Value & 0.024 & $-0.710^{* *}$ & \\
Jumlah tandan & r (Koefisien) & $0.304^{\text {tn }}$ & 0.010 & $-0.146^{\text {tn }}$ \\
& P Value & 0.336 & 0.239 & 0.651 \\
\hline
\end{tabular}

Keterangan : $* *=$ berbeda nyata pada taraf uji $1 \%, *=$ berbeda nyata pada taraf uji $5 \% \mathrm{tn}=$ tidak berbeda nyata

Trismiaty et al. (2008) menyatakan umur dan tingkat pendidikan tidak berpengaruh nyata terhadap produktivitas pemanen, sedangkan lama kerja dan upah berpengaruh terhadadap produktivitas pemanen. Hasil uji korelasi (Tabel 4) terhadap kualitas pemanen yang dinilai berdasarkan umur pemanen, lama kerja, dan tingkat pendidikan terhadap output pemanen (jumlah tandan) menunjukkan sifat yang tidak nyata, lemah, dan searah kecuali tingkat pendidikan yang bersifat berlawanan arah. Definisi dari hasil uji menunjukkan bahwa kenaikan atau bertambahnya umur pemanen dan lama kerja tidak akan berpengaruh secara signifikan terhadap output produksi. Selain itu, semakin tinggi jenjang pendidikan yang ditempuh pemanen dapat menurunkan output pemanen. Hal ini disebabkan oleh kemampuan seorang pemanen 
dalam memanen TBS diukur dengan kemampuan (skill), kondisi, dan tanggung jawab pemanen. Variabel lama kerja tidak berpengaruh terhadap output pemanen dapat disebabkan saat pengamatan terhadap pemanen terjadi penurunan produksi, sehingga data yang diperoleh kurang akurat.

Penulis mencoba untuk membandingkan kualitas pemanen dalam hal ini lama kerja (Tabel 5) dan umur pemanen (Tabel 6) terhadap output pemanen. Lama kerja dibagi berdasarkan yang telah bekerja kurang dari 5 tahun dan lebih dari 5 tahun. Hasil uji-t terhadap lama kerja menunjukkan bahwa lama kerja pemanen tidak berpengaruh nyata terhadap output yang dihasilkan. Pembagian umur pemanen berdasarkan yang berumur kurang dari 30 tahun dan lebih dari 30 tahun menurut hasil uji-t ternyata berpengaruh tidak nyata pula terhadap output yang dihasilkan pemanen. Trismiaty et al. (2008), semakin bertambahnya umur maka kekuatan fisik pemanen akan semakin menurun sehingga menurunkan output pemanen.

Tabel 5. Hasil uji-t lama kerja dengang ouput pemanen

\begin{tabular}{ccccc}
\hline \multirow{2}{*}{ Variabel } & \multicolumn{2}{c}{ Lama kerja } & \multirow{2}{t}{-} & $\operatorname{Pr}>\mathrm{t}$ \\
\cline { 2 - 3 } & $<5$ Tahun & $>5$ Tahun & hitung & \\
\hline $\begin{array}{c}\text { Output } \\
\text { pemanen }\end{array}$ & 70 & 68,33 & 0,2 & $0,85^{\text {tn }}$ \\
\hline Keterangan : $\mathrm{tn}=$ tidak berbeda nyata & &
\end{tabular}

Tabel 6. Hasil uji-t umur pemanen dengan output pemanen

\begin{tabular}{|c|c|c|c|c|}
\hline \multirow{2}{*}{ Variabel } & \multicolumn{2}{|c|}{ Umur pemanen } & \multirow{2}{*}{$\begin{array}{c}\mathrm{t}- \\
\text { hitung }\end{array}$} & \multirow{2}{*}{$\begin{array}{c}\mathrm{Pr}> \\
\mathrm{t}\end{array}$} \\
\hline & $<30$ Tahun & $>30$ Tahun & & \\
\hline $\begin{array}{l}\text { Output } \\
\text { pemanen }\end{array}$ & 71,33 & 67 & 0,68 & $\underset{\mathrm{tn}}{0,53}$ \\
\hline
\end{tabular}

Keterangan $:$ tn $=$ tidak berbeda nyata

Hasil uji korelasi maupun uji-t yang seluruhnya tidak berbeda nyata dapat diartikan bahwa kualitas pemanen baik dari segi umur pemanen, tingkat pendidikan, dan lama kerja tidak berpengaruh terhadap output pemanen. Akan tetapi, hasil korelasi dari tingkat pendidikan terhadap lama kerja menunjukkan sifat yang sangat nyata, erat dan berlawanan arah. Hal ini berarti tingkat pendidikan yang tinggi dari pemanen tidak berpengaruh terhadap output yang dihasilkan kecuali diimbangi dengan pengalaman kerja yang lebih lama. Trismiaty et al. (2008) menyatakan keterampilan pemanen dipengaruhi oleh lama kerja dan pengalaman pemanen.

\section{Pengawasan Panen}

Kegiatan panen sangat dibutuhkan kegiatan pengawasan sehingga kegiatan panen berlangsung sesuai dengan instruksi kerja. Keuntungan pengawasan panen yaitu mengurangi kesalahan panen dan memperkecil losses seperti brondolan tidak dikutip, pelepah tidak dipotong, tangkai tandan tidak dipotong pendek dan buah mentah tidak terpanen. Berdasarkan hasil pengamatan terhadap mutu buah (Tabel 7), 70\% pemanen sudah melakukan kegiatan panen sesuai dengan instruksi kerja. Namun, masih terdapat pemanen yang menurunkun buah fraksi 00 dan buah sakit. Hal ini dikarenakan kurangnya pemahaman pemanen tentang kriteria buah yang harus dipanen sehingga untuk mencapai basis mereka menurunkan buah mentah. Masalah tersebut biasanya diatasi dengan pemberian sanksi berupa denda dan peringatan oleh asisten afdeling ataupun surat peringatan (SP) untuk pelanggaran yang berulang.

Tabel 7. Kualitas mutu buah pemanen

\begin{tabular}{cccc}
\hline \multirow{2}{*}{ No pemanen } & \multicolumn{3}{c}{ Mutu buah } \\
\cline { 2 - 4 } & F 00 & Buah sakit & Buah matang \\
\hline 1 & 1 & 0 & 59 \\
2 & 1 & 2 & 61 \\
3 & 0 & 0 & 54 \\
4 & 0 & 0 & 58 \\
5 & 0 & 1 & 67 \\
6 & 0 & 0 & 55 \\
7 & 0 & 0 & 51 \\
8 & 0 & 1 & 76 \\
9 & 1 & 0 & 58 \\
10 & 0 & 1 & 73 \\
\hline Rata Rata & 0.3 & 0.5 & 61.2 \\
\hline
\end{tabular}

Sumber : Hasil pengamatan penulis (Mei 2013)

Pengawasan panen juga dilakukan terhadap kesalahan yang dilakukan pemanen. Berdasarkan Tabel 8, pemanen masih melakukan kesalahan seperti brondolan tidak dikutip, pelepah tidak dipotong 2 dan tidak disusun, tidak menurunkan pelepah yang seharusnya diturunkan, dan gagang tandan panjang $(>2.5 \mathrm{~cm})$ dan tidak dipotong berbentuk huruf "V". Berdasarkan Tabel 17, seluruh pemanen tidak mengutip brondolan yang seharusnya dikutip dan dikumpulkan di TPH. Hal ini dapat merugikan kebun karena mengurangi produksi harian yang ditargetkan. Dja'far (1992) menyatakan apabila rata-rata brondolan yang tidak terkutip adalah 3 butir per tandan, maka kerugian yang dialami oleh kebun adalah sekitar Rp5 747 ha $^{-1}$ tahun $^{-1}$.

Kesalahan pemanen juga terjadi pada bagian pemeliharaan pelepah, yaitu pelepah yang diturunkan tidak dipotong dua dan tidak disusun diantara pokok kelapa sawit. Sesuai instruksi 
kerja, pelepah yang diturunkan harus dipotong menjadi dua bagian dan disusun diantara pohon agar memudahkan pelapukan dan dapat menjadi pupuk organik yang sangat baik bagi tanaman kelapa sawit. Dari 19 pemanen yang diamati, hanya terdapat dua orang pemanen yang melakukan kesalahan tidak menurunkan pelepah yang seharusnya diturunkan. Pelepah tersebut harus diturunkan agar memudahkan dalam menurunkan TBS pada saat panen berlangsung. Pelepah yang tidak diturunkan maka menjadi sengkleh, sehingga dapat menjadi sumber penyakit pada tanaman kelapa sawit, menyulitkan pemanen, dan menyebabkan brondolan tersangkut di ketiak pelepah. Anwar dan Purba (2001), penunasan berat atau over pruning dapat menurunkan produksi karena tanaman menghasilkan bunga jantan yang lebih banyak, sedangkan penunasan yang terlambat akan meningkatkan kelembaban udara di sekitar pohon. Sebanyak $40 \%$ pemanen juga melakukan kesalahan dengan tidak memotong tangkai tandan (panjang tandan $<2.5 \mathrm{~cm}$ dan berbentuk huruf v). Tangkai tandan yang panjang akan menurunkan kadar minyak yang dihasilkan, sehingga menurunkan produksi minyak kelapa sawit.

Tabel 8. Tingkat kesalahan pemanen

\begin{tabular}{|c|c|c|c|c|}
\hline $\begin{array}{c}\text { Kemandoran/nama } \\
\text { pemanen }\end{array}$ & $\begin{array}{l}\text { Brondolan tidak } \\
\text { dikutip (butir) }\end{array}$ & $\begin{array}{l}\text { Pelepah tidak } \\
\text { dipotong } 2 \text { dan } \\
\text { tidak disusun } \\
\text { (pelepah) }\end{array}$ & $\begin{array}{c}\text { Tidak menurunkan } \\
\text { pelepah yang } \\
\text { seharusnya diturunkan } \\
\text { (Curi buah) (pelepah) }\end{array}$ & $\begin{array}{c}\text { Gagang tandan panjang } \\
(>2.5 \mathrm{~cm}) \text { dan atau tidak } \\
\text { dipotong berbentuk } \\
\text { huruf "V" (tandan) }\end{array}$ \\
\hline \multicolumn{5}{|l|}{ Mandor Ngatimin } \\
\hline Eman Prayogi & 36 & 0 & 0 & 2 \\
\hline Wagiman Tolo & 33 & 3 & 0 & 0 \\
\hline Sucipto & 36 & 0 & 0 & 0 \\
\hline Irwan & 30 & 5 & 0 & 0 \\
\hline M.Satria & 35 & 2 & 0 & 0 \\
\hline Ngatino & 35 & 0 & 0 & 0 \\
\hline Bobi Berkah & 30 & 2 & 0 & 2 \\
\hline Julisardi & 33 & 2 & 0 & 0 \\
\hline Sugito & 34 & 2 & 0 & 0 \\
\hline Ardiansyah & 33 & 2 & 0 & 0 \\
\hline Rata-rata & 33.5 & 1.8 & 0 & 0.4 \\
\hline \multicolumn{5}{|l|}{ Mandor Syamsul } \\
\hline Dedi Subarja & 32 & 0 & 0 & 0 \\
\hline Amin Saragih & 39 & 2 & 0 & 0 \\
\hline Joko Winarto & 25 & 0 & 4 & 0 \\
\hline Agus Rianto & 28 & 0 & 0 & 3 \\
\hline Suherman & 37 & 0 & 0 & 0 \\
\hline Wawan Syahputra & 31 & 3 & 3 & 2 \\
\hline Yasilan & 38 & 0 & 0 & 0 \\
\hline M.Rifaa'i & 32 & 3 & 0 & 0 \\
\hline Wirahardi & 34 & 3 & 0 & 0 \\
\hline Rata-rata & 32.9 & 1.6 & 0.8 & 0.6 \\
\hline
\end{tabular}

Sumber : Hasil pengamatan penulis (April-Mei 2013)

\section{Produktivitas Kelapa Sawit}

Keberhasilan dari suatu kegiatan pemanen dapat dilihat dari produksi yang mencapai target. Produksi yang mencapai target berarti manajemen kegiatan panen telah berjalan dengan baik dan sesuai dengan instruksi kerja. Produksi dapat diukur dengan produktivitas yang merupakan hasil pembagian dari produksi dibagi dengan luas lahan yang dipanen. Sunarko (2007) menyatakan potensi produksi tanaman kelapa sawit ditentukan oleh beberapa faktor seperti jenis atau varietas kelapa sawit, umur tanaman, pemeliharaan tanaman, keadaan iklim, serangan hama dan penyakit serta jenis tanah atau kelas kesesuaian lahan.
Produktivitas tanaman kelapa sawit yang ditanam ditanah subur memiliki produktivitas yang lebih tinggi dengan yang ditanam di tanah yang miskin hara. Kondisi tanah di Kebun Gunung Pamela adalah typic hapluduits dan masuk kedalam kesesuaian lahan S3. Tanah jenis ini memerlukan penanganan dan pengelolaan yang khusus untuk meningkatkan produktivitas kelapa sawit seperti pemberian pupuk anorganik yang cukup tinggi dan berimbang dengan konservasi tanah dan air yang tepat dan berkesinambungan (Koedadiri 2004). Produktivitas kelapa sawit di kebun Gunung Pamela berdasarkan Tabel 9 belum sesuai dengan 
standar Marihat PPKS. Hal ini dapat dikarenakan kondisi iklim dan tanah, belum maksimalnya kegiatan aspek teknis (pemupukan dan pengendalian gulma), pencurian TBS di hanca maupun TPH, kegiatan panen yang tidak sesuai intruksi kerja dan kurangnya pengawasan panen.

Tabel 9. Produktivitas kelapa sawit 5 tahun terakhir

\begin{tabular}{|c|c|c|c|c|c|c|c|c|c|c|}
\hline \multirow{3}{*}{ TT } & \multicolumn{10}{|c|}{ Produktivitas } \\
\hline & \multicolumn{2}{|c|}{2008} & \multicolumn{2}{|c|}{2009} & \multicolumn{2}{|c|}{2010} & \multicolumn{2}{|c|}{2011} & \multicolumn{2}{|c|}{2012} \\
\hline & $\mathrm{P}$ & $\mathrm{SM}$ & $\mathrm{P}$ & SM & $\mathrm{P}$ & SM & $\mathrm{P}$ & $\mathrm{SM}$ & $\mathrm{P}$ & SM \\
\hline 1998 & 17.93 & 28.0 & 18.88 & 29.0 & 18.42 & 30.0 & 20.06 & 30.0 & 21.90 & 29.5 \\
\hline 2000 & 22.23 & 26.0 & 20.63 & 27.0 & 19.24 & 28.0 & 22.80 & 29.0 & 22.93 & 30.0 \\
\hline
\end{tabular}

Sumber : Kantor besar Gunung Pamela

Keterangan : $\mathrm{P} \quad=$ Produktivitas $\left(\mathrm{kg} \mathrm{ha}^{-1}\right), \mathrm{SM}=$ Standar Marihat $\left(\mathrm{kg} \mathrm{ha}^{-1}\right)$

Produktivitas kelapa sawit di Afdeling V terdapat perbedaan antar kapveld. Hasil uji-t (Tabel 10) produktivitas antar kapveld menunjukkan sifat yang nyata dan tidak berbeda nyata. Hasil berbeda nyata antar kapveld tampak pada kapveld I dengan kapveld III dan kapveld IV serta kapveld III dengan kapveld IV, sedangkan untuk perbandiangan kapveld lainnya bersifat tidak nyata. Hal ini dikarenakan kapveld I dijadikan sumber produksi dibandingkan dengan kapveld yang lain. Kapveld I hampir kesuluruhan tanaman terdapat pada daerah datar sedangkan kapveld lainnya berada pada daerah datar hingga lereng. Kondisi lereng menyulitkan pemanen untuk menurunkan TBS sehingga banyak buah yang tidak terpanen atau buah tinggal. Hal ini pula yang menjadi salah satu penyebab produktivitas tidak sesuai dengan target. Anwar (2001) menyatakan penanaman tanpa teras pada areal dengan kemiringan lereng $>6^{\circ}$ dapat menurunkan produksi sebesar $20 \%$ dan memperlambat masa panen sekitar 6 bulan. Optimalisasi produksi yang telah dilakukan oleh kebun sebagai upaya dalam mengatasi kendala tersebut adalah pembuatan jalan transportasi. Jalan transportasi merupakan akses jalan yang dibuat pada daerah kaki lereng sehingga memudahkan pemanen untuk mengumpulkan buah ke tempat pengumpulan hasil (TPH).

Tabel 10. Hasil uji t produktivitas antar kapveld

\begin{tabular}{|c|c|c|c|c|c|c|}
\hline \multirow{2}{*}{ Perbandingan kapveld } & \multicolumn{4}{|c|}{ Nilai tengah $\left(\mathrm{kg} \mathrm{ha}^{-1} \operatorname{hari}^{-1}\right)$} & \multirow{2}{*}{ t-hit } & \multirow{2}{*}{$\operatorname{Pr}>|t|$} \\
\hline & Kapveld I & Kapveld II & Kapveld III & Kapveld IV & & \\
\hline Kapveld I x Kapveld II & 446.605 & 291.066 & 292.891 & 153.349 & 2.36 & $0.1^{\mathrm{tn}}$ \\
\hline Kapveld I x Kapveld III & & & & & 3.75 & $0.033^{*}$ \\
\hline Kapveld I x Kapveld IV & & & & & 3.86 & $0.031 *$ \\
\hline Kapveld II x Kapveld III & & & & & -0.04 & $0.974^{\mathrm{tn}}$ \\
\hline Kapveld II x Kapveld IV & & & & & 1.45 & $0.242^{\text {tn }}$ \\
\hline Kapveld III x Kapveld IV & & & & & 2.85 & $0.065^{*}$ \\
\hline
\end{tabular}

Keterangan : $*=$ berbeda nyata pada taraf uji $5 \%, \mathrm{tn}=$ tidak berbeda nyata

\section{KESIMPULAN}

Fungsi manajemen terdiri atas merencanakan (planning), mengorganisasi (organizing), memimpin (leading) dan mengendalikan (controlling). Aspek utama manajemen panen kelapa sawit terletak pada rotasi panen, penentuan nilai AKP, tenaga kerja, pengawasan panen dan upaya dalam mempertahankan produktivitas. Rotasi panen di Afdeling V dibagi menjadi dua, yaitu semester I dan II yang dijadwalkan sesuai dengan tinggi rendahnya produksi.

Penentuan nilai AKP merupakan faktor utama dalam kegiatan panen karena menentukan estimasi produksi, jumlah tenaga kerja dan jumlah armada yang dibutuhkan. Penentuan nilai AKP yang sebagian besar kurang akurat menyebabkan tidak sesuainya jumlah produksi.

Pengawasan panen berupa pengecekan mutu buah maupun mutu hanca yang diamati selama penelitian secara garis besar sudah baik. Kesalahan pemanen terletak pada pemeliharaan pelepah yang tidak dipotong dua dan disusun. Kualitas tenaga kerja panen dapat meningkat sesuai dengan lama kerja pemanen dalam suatu kebun. Optimalisasi produksi merupakan salah satu upaya untuk mengatasi hambatan panen. 


\section{DAFTAR PUSTAKA}

Anwar, S., Purba, P. 2001. Kesenjangan produksi pada tanaman kelapa sawit muda : suatu tantangan bagi pekebun kelapa sawit. Warta PPKS. 9(2):51-59

Astra Agro Niaga. 1996. Pedoman Brevet Dasar II. Tanaman Kelapa Sawit. Jakarta (ID): Astra Agro Niaga.

[Ditjenbun] Direktorat Jenderal Perkebunan. 2010. Volume dan nilai ekspor, impor Indonesia [internet]. http://ditjebun.deptan.go.id. [diunduh 12 Oktober 2012].

Dja'far,, D. 1992. Pengaruh pengutipan brondolan kelapa sawit terhadap pendapatan petani. Berita Penelitian Perkebunan. 2(1):33-38.

Koedadiri, A.D. 2004. Produktivitas kelapa sawit generasi pertama pada tanah ultisol di beberapa wilayah perkebunan kelapa sawit Indonesia. Warta PPKS. 12(2-3):47-59.

Pahan, I. 2008. Panduan Lengkap Kelapa Sawit. Jakarta (ID): Penebar Swadaya.

[PPKS] Pusat Penelitian Kelapa Sawit (PPKS). 2003. Budidaya Kelapa Sawit. Medan (ID) : Pusat Penelitian Kelapa Sawit.
[PPKS] Pusat Penelitian Kelapa Sawit. 2007. Budidaya Kelapa Sawit. Medan (ID): Pusat Penelitian Kelapa Sawit.

Setiawan, K. 2012. Manajemen Panen Kelapa Sawit (Elaeis guineensis Jacq.) pada Lahan Gambut di kebun Mandah, PT. Bhumireksa Nusa Sejati, Minamas Plantation [skripsi]. Bogor (ID): Institut Pertanian Bogor.

Sarimanah. 2008. Manajemen Panen di Perkebunan Kelapa Sawit (Elaeis guineensis Jacq.) Mustika Estate, PT. Sajang Heulang, Minamas, Kalimantan Selatan [skripsi]. Bogor (ID): Institut Pertanian Bogor

Robbins, S.P., Coulter, M. 2005. Manajemen. Slamet H, penerjemah; Indriani, editor. Jakarta (ID): PT Indeks. Terjemahan dari: Management. Ed ke-8.

Sunarko. 2007. Petunjuk Praktis Budi Daya dan Pengolahan Kelapa Sawit. Jakarta (ID): Agromedia Pustaka.

Sunarko. 2009. Budidaya dan Pengelolaan Kebun Kelapa Sawit dengan Sistem Kemitraan. Jakarta (ID): Agromedia Pustaka.

Trismiaty, Listyani, Mubaraq, T.Z. 2008. Manajemen tenaga kerja kelapa sawit di PT Perkebunan III (Persero) Kebun Aek Nabara Selatan Labuhan Batu Sumatera Utara. Buletin Ilmiah Instiper. 15(1):15-23. 